\title{
Seasonal variation in month of diagnosis in children and adolescents with acute lymphoblastic leukemia: 15-year trends at a single center
}

\author{
Jose Jaime-Perez ${ }^{1}$, Marcela Hernández-Coronado ${ }^{1}$, José Hernández-De los Santos ${ }^{1}$, and \\ David Gomez-Almaguer ${ }^{2}$ \\ ${ }^{1}$ Hospital Universitario \\ ${ }^{2}$ School of Medicine and "Dr. José E. González" of the Autonomous University of Nuevo \\ León
}

June 10, 2020

\begin{abstract}
Background: The date of acute lymphoblastic leukemia (ALL) diagnosis has been studied regarding potential etiologic roles with contrasting results and the issue remains controversial. We analyzed seasonality of diagnosis in a homogenous Hispanic cohort. Design/Method: Clinical files and electronic databases of consecutive children and adolescents with ALL in Northeast Mexico over 2004-2018 were scrutinized. Data included date of diagnosis, age, sex, and risk group. Patients were divided into children $<16$ and adolescents 16 to 20 years. Statistical analysis included Chi-square tests for heterogeneity and multiple Poisson regression using parametric harmonic modelling to detect monthly variation. Results: During the fifteen-year study period 394 consecutive patients with ALL were included. There were $323(81.9 \%)$ children, and 71 (18.1\%) adolescents. 176 $(54.5 \%)$ children had high-risk disease. Heterogeneity across months of diagnosis was confirmed ( $\mathrm{P}=0.038)$. A statistically significant monthly variation in the date of diagnosis documented by Poisson regression was found for the whole group, with a peak on March $(\mathrm{P}<0.001)$. When analyzing by age group, cases of children with ALL predominated in March. Adolescents had a separate peak in July, with a 4.5: 1 male to female ratio. Conclusions: Seasonality at month of diagnosis in children and adolescents with ALL was identified. Male adolescents had a high July peak suggesting a hormonal influence in ALL development in this age group.
\end{abstract}

\section{INTRODUCTION}

Acute lymphoblastic leukemia (ALL) represents the most common childhood malignancy, accounting for approximately $28 \%$ of cancers and $80 \%$ of all leukemias in children ${ }^{1,2}$. ALL presentation is bimodal, with the first peak occurring in childhood, and a second peak around age fifty ${ }^{1}$. Its incidence is reported to be higher in Hispanic children at 43 cases per million vs. 28 in non-Hispanics ${ }^{3}$ and in Mexico it has been reported at 49.5 cases per million. ${ }^{4}$

The pathogenesis of ALL is complex and remains elusive, exogenous and/or endogenous exposures, genetic susceptibility, biologic heterogeneity, and chance appear to have roles ${ }^{5,6}$. Environmental risk factors including infections are an area of particular interest in leukemia's etiology ${ }^{7,8}$ and epidemiological investigation into the periodicity of leukemia onset, which has a long history, and the evidence for seasonal variation in incidence may provide insight into this hypothesis ${ }^{9}{ }^{10}$. Many viral infections have characteristic seasonal onsets, thus investigations had suggested that ALL is related to infection or other seasonally-varying environmental risk factors ${ }^{11-13}$.

Seasonal variation in diagnosis of children with ALL may provide evidence of an infectious etiology for childhood ALL, as seasonal climatic changes give rise to respiratory infections or gastrointestinal infections in winter, spring, and summer. This might possibly suggest the presence of environmental factors such as 
pesticides, which are applied frequently in rural areas. Also, spatiotemporal clusters occur, with an excess of childhood ALL cases observed in a determined geographical area at certain points in time compared with other areas and other times. ${ }^{14}$ Importantly, most studies reporting seasonal trends do so in countries with temperate-cool climates ${ }^{15}$, with a few conducted in arid or semiarid regions, which have a rather short winter season ${ }^{16}$.

Studies addressing the seasonality of presentation in acute leukemia report contrasting results ${ }^{17-20}$. Time trends and seasonal variations have been assessed, while some have not identified a seasonal pattern ${ }^{20,21}$, others have found significant seasonal influence ${ }^{17,19,22}$. Most studies on this subject have analyzed different reference dates, including birth date, first symptom date or diagnosis date, and used different statistical methods, leading to inconsistencies and controversy in the results. The evidence obtained may contribute to learn about potential seasonally varying environmental risk factors, such as infections or pesticide exposure, especially in Latin America where this pattern is less clear, with few reports documenting this aspect of childhood and adolescence ALL.

The present study aimed to investigate the presence of seasonal variation in month of diagnosis in a homogeneous ethnic and socioeconomic group of Hispanic children and adolescents with ALL in a low-middle income population over a 15-year period.

\section{METHODS}

\section{Study population}

A fifteen-year observational, longitudinal, and retrospective analysis of patients $<20$ years of age with ALL diagnosis, classified according to the World Health Organization ${ }^{23}$ from 2004 to 2018 at the Hematology Department of the Dr. Jose E. González University Hospital of the School of Medicine of the Universidad Autonoma de Nuevo Leon, in Monterrey, México was performed. The region is semiarid and has a latitude of $25^{\circ} 40^{\prime} 17^{\prime \prime}$ North and longitude of 100deg18'31" West. The institution is a referral center for three States in Northeast Mexico adding up to a population of 11.5 million; patients with no formal healthcare services coverage are referred from public primary and secondary care centers. Hence, taking into consideration the lack of a national registry that records all cases of ALL over the study period the patients included could represent the uninsured population of Northeast Mexico.

We analyzed clinical and electronic files of 394 patients and included patients' age, sex, risk group and date of diagnosis. For the purposes of this study we considered date of diagnosis as the date of first pathological data registered and only consecutive patients with symptom-diagnosis interval $<4$ weeks were included in the study to minimize the bias generated due to delayed presentation on seasonality. Also, for the purposes of this study, the term seasonality refers to a pattern, variation, or fluctuation in the month of ALL diagnosis. No patient was excluded due to lack of data. The Institutional Ethics and Research Committee approved the study protocol and waived informed consent due to its retrospective methodology.

Statistical Analysis

Patients were classified by age group, considering children those under 16 years of age and adolescents from 16 to 20 years. Children were classified by risk group according to the Children's Oncology Group approach and the National Comprehensive Cancer Network 2020 Guidelines. ${ }^{24}$ Next, Poisson regression models were used to determine the pattern of seasonality in the diagnosis date of patients with ALL. This method fits sinusoidal (harmonic) models to the data, using observed counts as the outcome and expected counts and month of diagnosis as covariates. The significance of the sinusoidal model assumption was evaluated with post-estimation Pearson chi-square tests for goodness-of-fit and Akaike information criterion/Bayesian information criterion. The overall temporal trend was also tested applying a Poisson regression model.

All models were evaluated for significant trends using post-estimation statistics.

Stratified analyses were also performed for gender and age groups as well as for group of risk in children. We used a chi-square test of homogeneity to prove the hypothesis of no difference in number of ALL diagnoses 
by month. Tests were performed separately for males and females, children and adolescents. SPSS v.26 (IBM SPSS Statistics, IBM Corporation, Armonk, NY) was used for data analysis. A P-value [?] 0.05 was considered statistically significant.

\section{RESULTS}

Descriptive characteristics of patients with ALL are displayed in Table 1. For the period 2004-2018, the study included 394 patients with a male preponderance of $220(55.8 \%)$ vs. 174 females $(44.2 \%)$, and a male-to-female ratio of $1.26,(P=0.011)$. There were 323 children $(81.9 \%)$, and 71 adolescents $(18.1 \%)$. For the whole group, median age at diagnosis was 7 years $(2$ months -20 years); median age for females was 5 years (2 months -20 years) vs. 8.5 years $(3$ months -20 years $)$ for males $(P=0.009)$. Median follow-up was 32 months $(1-171)$. In the group of children there were 172 males $(53.3 \%)$ and 151 females $(46.7 \%)$, $(P=0.243)$. For adolescents there were 48 males $(67.6 \%)$ and 23 females $(32.4 \%),(P=0.003)$. Additional data are shown in Table 1.

\section{$A L L$ through the years of the study}

The presentation of ALL cases through the years of 2004- 2018 showed a heterogeneous distribution $(\mathrm{P}=0.179)$. The year with the maximum number of cases was 2005 , with thirty-seven diagnoses, whereas 2016 was the year with the lowest number, eighteen. An increase in childhood and adolescence ALL cases of $54.5 \%$ over the last 3 years, from 2016 to 2018, was documented (Figure 1).

\section{Month of Diagnosis}

Monthly heterogeneity for all 394 cases was statistically significant using the chi-square test $(\mathrm{P}<0.038)$ (Table 2), which indicated a non-uniform distribution of cases; in stratified analyses no such effect was found among males $(P=0.514)$, females $(P=0.952)$, children $(P=0.163)$ and adolescents $(P=0.304)$.

The Poisson regression modelling indicated that the month in which an annual peak was observed was March (10.7\% of all cases(Figure 2). The month with the lowest number of cases was September (5.8\% of all cases). Considering patients of all ages, $13.6 \%$ of the male cases were diagnosed in July, while only $5.7 \%$ of females were diagnosed in this month.

\section{Children}

The three months of maximum cases in children were March (10.8\%), May (10.8\%), and October (10.2\%), adding up to $31.8 \%$ of childhood diagnoses. The minority of children ALL cases presented in December (5.6\%), September (5.9\%), and November (6.5\%), explaining only $18 \%$ of ALL diagnoses (Figure 3A); further analysis of the whole cohort by sex is presented(Figure $3 B$ ). In males, three main peaks were found: in July, October (12.1\% each) and in March (11\%), adding up to $35.2 \%$. (Figure 4A). Females had only one main peak in May, accounting for $14.3 \%$. When classified by risk group, $176(54.5 \%)$ children were high-risk and $147(45.5 \%)$ standard-risk patients. May was the month with the highest peak for high-risk patients $(11.8 \%)$, while October had the highest peak for the standard-risk group (12.1\%). The month with the lowest number of ALL cases for high-risk patients was January (6.25\%) and for the standard risk group it was September (4\%). (Figure 4B).

\section{Adolescents}

Adolescents $(\mathrm{n}=71)$ presented a peak in the month of July $(14.9 \%)$ (Figure $3 A)$, males $(\mathrm{n}=48)$ were responsible for $81 \%$ of this peak, while the months with the lowest number of cases were June $(4.2 \%)$ and September (5.6\%). The highest number of ALL diagnoses in female adolescents presented in March (15.5\%) and May (15.5\%); for males it was July $(17.6 \%)$ (Figure 4 C)

\section{DISCUSSION}

Analyses of children and adolescents' ALL cases at a single reference center in Northeast Mexico for the fifteen years between 2004 and 2018 provide evidence for seasonal variation in month of diagnosis with a peak in March. Our study contributes with a contemporary analysis of a homogeneous ethnic and socioeconomic 
group. Contrary to our findings, the single previous study addressing seasonality of diagnosis in a Hispanic population concluded that an ALL peak did not repeat periodically in their six-year time series ${ }^{20}$. A study in a Middle Eastern country did not find a seasonal effect related to month of diagnosis either ${ }^{21}$. A reduced number of years was assessed in both reports, this could explain their lack of a trend in ALL seasonality. Conversely, our findings support those of a large 17-year French study that found seasonal variation in 1 to 6 years old males with an increase of the incidence in April, August and December. ${ }^{25}$

In 1934 Lambin and Gerard, the pioneers of studies to establish a relationship between leukemia and the season of year, concluded that there was a peak incidence from November to February in Belgium population 22. Studies from the United States ${ }^{26}$, Italy ${ }^{27}$, and Denmark ${ }^{15}$ highlighted the elevated incidence during the winter months; contrarily, in England and Wales, the largest number of ALL cases occurred in summer ${ }^{28}$. Additionally, one study conducted in Southern China including patients of all ages analyzed the monthly distribution for onset of ALL symptoms and found a peak in July ${ }^{29}$ Contrary to these positive findings, a review of twenty-four reports from eleven countries in locations ranging from 35.05deg South to 65.01deg North found no pattern of seasonality, and the hypothesis of increasing ALL incidence as the latitude of the study population moved away from the equator was rejected ${ }^{19}$.

The precise etiology of ALL has not been established, only exposure to radiation in utero and Down syndrome have been recognized as risk factors associated with this malignancy; yet, these account for a very small part of cases. ${ }^{30}$ Environmental risk factors including infections, radiation, electric energy sources, and other causes have long been suspected to play an important role in the development of the disease ${ }^{31-33}$. A multistage two-hit model has been proposed with the first hit of genetic susceptibility possibly occurring before conception or in the prenatal stage and the second hit ensuing in the extrauterine life through environmental exposure. ${ }^{34,35}$ Previous reports suggest that antigenic stimulation after community acquired infections may activate oncogenes or disrupt tumor suppressor genes ${ }^{36},{ }^{37}$ and thus seasonal changes in incidence of ALL in the context of an infectious etiology have been studied, with mixed results ${ }^{6,13,38}$. Our findings document the existence of a monthly seasonal pattern in the study group and appear to support the putative role of infections as a second hit influencing ALL development in Hispanic children.

The influence of risk-group on season of ALL diagnosis has not been previously reported; we assessed it and found that May was the month with the greater number of high-risk ALL diagnoses, while for the standard-risk group it was October. Remarkably, a distinctive peak of male adolescents with ALL was identified in July, while females had peaks in March and May. Seasonality in the diagnosis of ALL in adolescents and its conspicuous male predominance has not been previously reported, confirming that ALL in adolescents has a distinctive biologic behavior, evolution, and clinical characteristics, underscoring that specific research needs for this age group should be addressed. In this respect. a previous study in adolescents in the United States supports the existence of important seasonal variation in the cumulative risk of ALL among youthful populations; the possibility that seasonal factors, including environmental allergens and/or infectious agents, promote malignancy via indirect mechanisms was proposed ${ }^{38}$. Hormonal fluctuations, especially during puberty, may play an important role in the increased cancer incidence, especially ALL, among male individuals. The influence of sex hormones in hematological diseases has been previously addressed $^{39-41}$. In this context, sexual dimorphism in adolescents with ALL, with a global 2:1 male to female ratio in the second decade of life, has been recently reported ${ }^{42}$.

In conclusion, ALL seasonal variation was found in our fifteen-year analysis, and March was identified as the peak month for its diagnosis in our study group of almost four-hundred consecutive children and adolescents. In male adolescents, a distinctive peak emerged in July, underscoring the need for further studies to identify particular risk factors in this group.

\section{CONFLICT OF INTEREST}

The authors declare that there is no conflict of interest.

\section{ACKNOWLEDGEMENTS}


We thank Sergio Lozano-Rodriguez, M.D., for his help in editing the manuscript.

\section{REFERENCES}

1. Siegel RL, Miller KD, Jemal A. Cancer statistics, 2020. CA Cancer J Clin 2020;70:7-30.

2. Terwilliger T, Abdul-Hay M. Acute lymphoblastic leukemia: a comprehensive review and 2017 update. Blood Cancer J 2017;7:577.

3. McNeil DE, Cote TR, Clegg L, Mauer A. SEER update of incidence and trends in pediatric malignancies: Acute lymphoblastic leukemia.Med Pediatr Oncol 2002;39:554-557.

4. Perez-Saldivar ML, Fajardo-Gutierrez A, Bernaldez-Rios R, et al. Childhood acute leukemias are frequent in Mexico City: Descriptive epidemiology. BMC Cancer 2011;11.

5. Zuckerman T, Rowe JM. Pathogenesis and prognostication in acute lymphoblastic leukemia. F1000 Prime Reports 2014;6:3-7.

6. Inaba H, Greaves M, Mullighan CG. Acute lymphoblastic leukaemia.Lancet 2013;381:1943-1955.

7. Greaves MF. Aetiology of acute leukaemia. Lancet1997;349:344-349.

8. Kinlen LJ. High contact paternal occupations, infection and childhood leukaemia: Five studies of unusual population mixing of adults. Br J Cancer 1997;76:1539-1545.

9. McNally RJQ, Eden O. An infectious aetiology for childhood acute leukaemia: A review of the evidence. Br J Haematol2004;127:243-263.

10. Goujon S, Kyrimi E, Faure L, et al. Spatial and temporal variations of childhood cancers: Literature review and contribution of the French national registry. Cancer Med 2018;7:5299-5314.

11. Timonen TTT. A hypothesis concerning deficiency of sunlight, cold temperature, and influenza epidemics associated with the onset of acute lymphoblastic leukemia in northern Finland. Ann Hematol1999;78:408414.

12. O'Connor SM, Boneva RS. Infectious etiologies of childhood leukemia: Plausibility and challenges to proof. Environ Health Perspect2007;115:146-150.

13. Karimi M, Yarmohammadi H. Seasonal variations in the onset of childhood leukemia/lymphoma: April 1996 to March 2000, Shiraz, Iran.Hematol Oncol 2003;21:51-55.

14. Perez-Saldivar M, Rangel-Lopez A, Fajardo-Gutierrez A, Mejia-Arangure J. Environmental Factors and Exposure Time Windows Related to the Etiology of Acute Lymphoblastic Leukemia in Children. In:Etiology of Acute Leukemias in Children . ; 2016.

15. Sorensen H, Pedersen L, Olsen JH. Seasonal Variation in Month of Birth and Diagnosis of Early Childhood Acute Lymphoblastic Leukemia.JAMA 2001;285:168-169.

16. Bagirov I. The seasonal dynamics of morbidity of acute lymphoblastic leukemia in Azerbaijan. Probl sotsial'noi Gig Zdr i Istor meditsiny 2019;5:911-914.

17. Westerbeek RMC, Blair V, Eden OB, et al. Seasonal variations in the onset of childhood leukaemia and lymphoma. Br J Cancer1998;78:119-124.

18. Gao F, Nordin P, Krantz I, Chia KS, Machin D. Variation in the seasonal diagnosis of acute lymphoblastic leukemia: Evidence from Singapore, the United States, and Sweden. Am J Epidemiol2005;162:753-763.

19. Gao F, Chia KS, Machin D. On the evidence for seasonal variation in the onset of acute lymphoblastic leukemia (ALL). Leuk Res2007;31:1327-1338.

20. Santoyo-Sanchez A, Ramos-Penafiel C, Palmeros-Morgado G, et al. Clinical features of acute leukemia and its relationship to the season of the year. Rev Med Inst Mex Seguro Soc 2014;52:176-181. 
21. Sahin D, Yigenoglu TN, Saygili O, et al. Adult acute leukemia and seasonality: a single center experience. HemaSphere 2019;3.

22. Lambin P GM. Seasonal variation in the frequency of acute leukemia. [In French.]. Sang 1934;8:730-732.

23. Arber D, Orazi A, Hasserjian R, et al. The 2016 revision to the World Health Organization (WHO) classification of myeloid neoplasms and acute leukemia. Blood 2016;127.

24. Brown P, Inaba H, Annesley C, et al. Pediatric Acute Lymphoblastic Leukemia, Version 2.2020, NCCN Clinical Practice Guidelines in Oncology.J Natl Compr Canc Netw 2020;18:81-112.

25. Goujon-Bellec S, Mollie A, Rudant J, Guyot-Goubin A, Clavel J. Time trends and seasonal variations in the diagnosis of childhood acute lymphoblastic leukaemia in France. Cancer Epidemiol2013;37:255-261.

26. Hayes DM. The seasonal incidence of acute leukemia. A contribution to the epidemiology of the disease. Cancer 1961;14:1301-1305.

27. Scanu A. Seasonal frequency of acute and subacute leukemia in Campania and Sardegna: statistical study [in italian]. Riforma Med 1954;68:449-452.

28. Lee. JAH. Seasonal Variation in Leukaemia Incidence. Br Med J1963:623.

29. Li SY, Ye JY, Meng FY, Li CF, Yang M. Clinical characteristics of acute lymphoblastic leukemia in male and female patients: A retrospective analysis of 705 patients. Oncol Lett2015;10:453-458.

30. Eden T. Aetiology of childhood leukaemia. Cancer Treat Rev2010;36:286-97.

31. Greaves MF, Alexander FE. An infectious etiology for common acute lymphoblastic leukemia in childhood? Leukemia 1993;7:349-360.

32. Jabbour EJ, Faderl S, Kantarjian HM. Adult acute lymphoblastic leukemia. Mayo Clin Proc 2005;80:1517-1527.

33. Hein D, Borkhardt A, Fischer U. Insights into the prenatal origin of childhood acute lymphoblastic leukemia. Cancer Metastasis Rev2020:14-16.

34. Greaves M. Pre-natal origins of childhood leukemia. Rev Clin Exp Hematol 2003;7:233-245.

35. Greaves MF, Maia AT, Wiemels JL, Ford AM. Leukemia in twins: lessons in natural history. Blood 2003;102:2321-2333.

36. Heidari N, Sc M, Abroun S, et al. Significance of inactivated genes in leukemia: Pathogenesis and prognosis. Cell J 2017;19:9-26.

37. Musolino C, Allegra A, Minciullo PL, Gangemi S. Allergy and risk of hematologic malignancies: Associations and mechanisms. Leuk Res2014;38:1137-1144.

38. Harris RE, Harrell FE, Patil KD, Al-Rashid R. The seasonal risk of pediatric/juvenile acute lymphocytic leukemia in the United States.J Chronic Dis 1987;40:915-923.

39. Allain EP, Venzl K, Caron P, et al. Sex-dependent association of circulating sex steroids and pituitary hormones with treatment-free survival in chronic lymphocytic leukemia patients. Ann Hematol2018;97:16491661.

40. Trigunaite A, Dimo J, Jorgensen TN. Suppressive effects of androgens on the immune system. Cell Immunol 2015;294:87-94.

41. Yang H, Chen C-M, Yan P, et al. The androgen receptor gene is preferentially hypermethylated in follicular non-Hodgkin's lymphomas. Clin Cancer Res 2003;9:4034-4042. 
42. Jaime-Perez JC, Hernandez-De los Santos JA, Fernandez LT, Padilla-Medina JR, Gomez-Almaguer D. Sexual Dimorphism in Children and Adolescents With Acute Lymphoblastic Leukemia. J Pediatr Hematol Oncol 2019;00:1.

\section{Availability of data}

The data that support the findings of this study are available on request from the corresponding author. The data are not publicly available due to privacy or ethical restrictions.

\section{FIGURE LEGENDS}

FIGURE 1 Children and adolescents with acute lymphoblastic leukemia (ALL) between 2004-2018

FIGURE 2 Diagnoses of ALL with Poisson harmonic regression trend line. Poisson harmonic regression, sinusoidal model post-estimation P-value (Pearson $X^{2}$ goodness of-fit)

FIGURE 3A Seasonal variation in month of diagnosis for 394 patients with ALL between 2004 and 2018 stratified by age group (children and adolescents) B Seasonal variation in month of diagnosis for 394 patients with ALL between 2004 and 2018 stratified by sex

FIGURE 4 A Seasonal variation in month of diagnosis for 323 children with ALL between 2004 and 2018 stratified by sex. Three peaks were identified in males, corresponding to March, July, and October. Females exhibited a single peak in MayB. Seasonal variation in month of diagnosis for 323 children with ALL between 2004 and 2018 stratified by risk group; high-risk group had its maximun peak in May, while standard-risk cases prevailed in October. C. Seasonal variation in month of diagnosis for 71 adolescents with ALL between 2004 and 2018 stratified by sex. There was a peak of maximum number of cases in July and a 4.5 to 1 male to female ratio in this month

\section{Hosted file}

TABLE 1.docx available at https://authorea.com/users/331786/articles/458339-seasonalvariation-in-month-of-diagnosis-in-children-and-adolescents-with-acute-lymphoblasticleukemia-15-year-trends-at-a-single-center

\section{Hosted file}

TABLE 2.docx available at https://authorea.com/users/331786/articles/458339-seasonalvariation-in-month-of-diagnosis-in-children-and-adolescents-with-acute-lymphoblasticleukemia-15-year-trends-at-a-single-center 


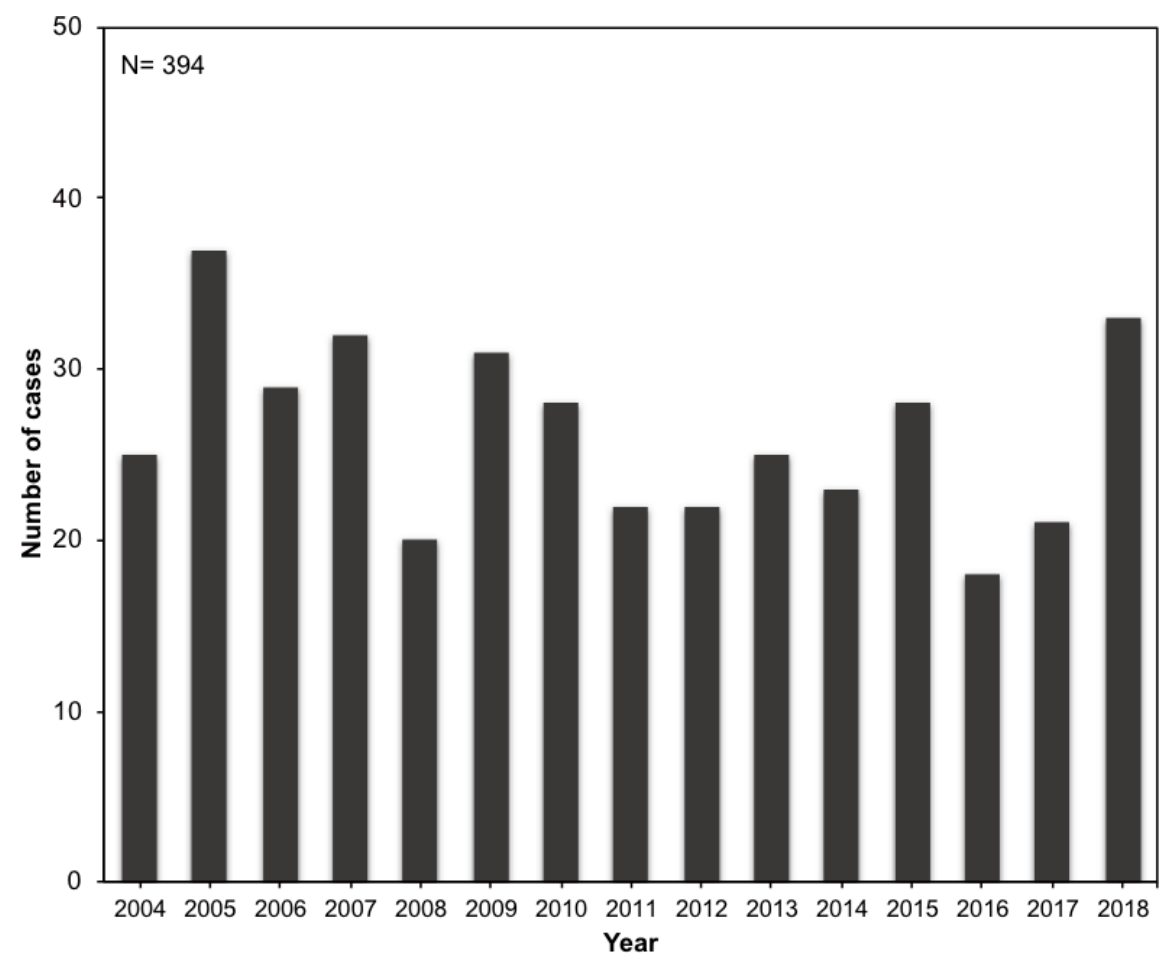

Diagnoses of ALL, years 2004-2018

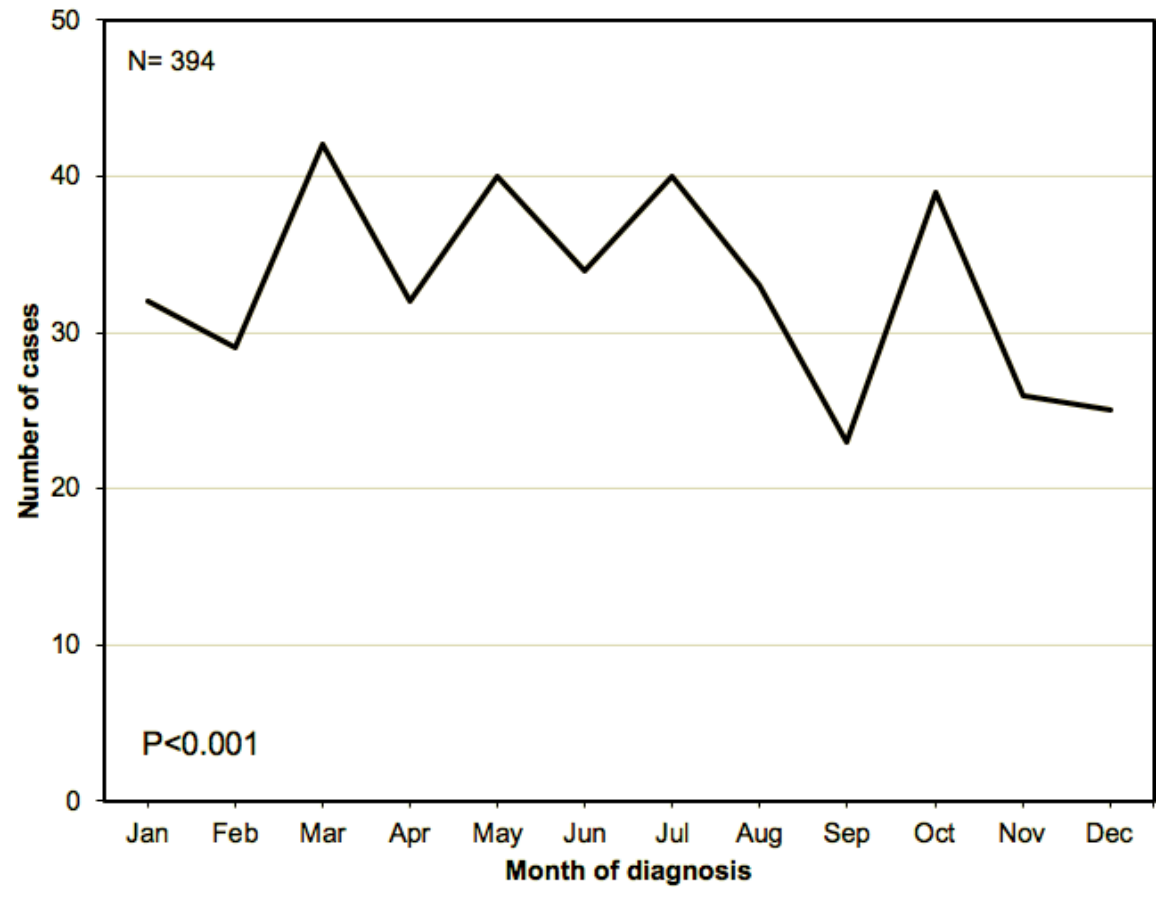



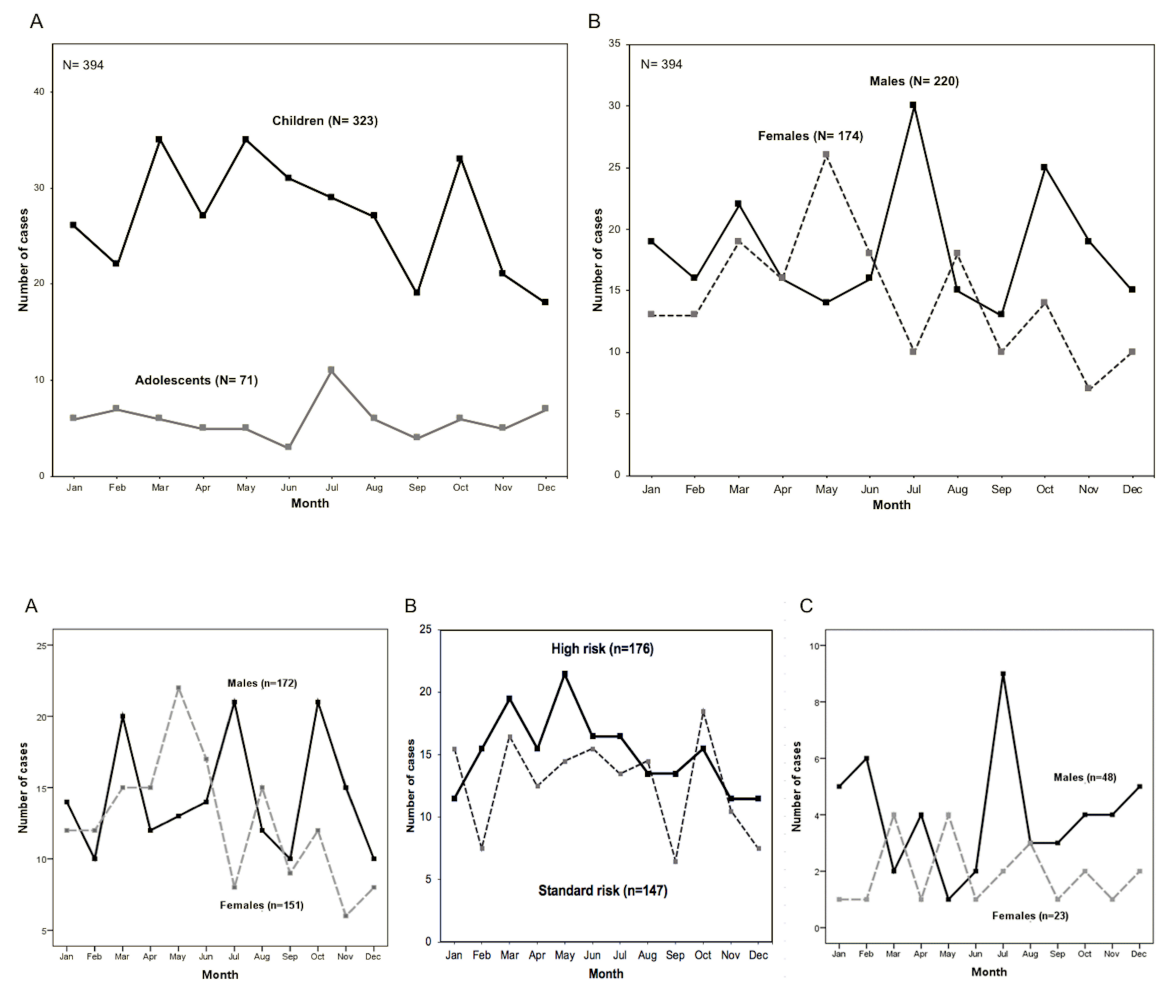